\title{
The Impact of Intrinsic and Extrinsic Rewards on Teachers Creativity
}

\author{
Ahmed Chand* \\ Department of Commerce and Finance, Superior University, Lahore, Pakistan \\ Nimra Ashraf \\ Department of Economics, Superior University, Lahore, Pakistan \\ Laila Khalid \\ Department of Economics, Superior University, Lahore, Pakistan \\ Husnain Munawar \\ Department of Banking and Finance, Government College University, Faisalabad, Pakistan
}

\begin{abstract}
The research is financed by Asian Development Bank. No. 2006-A171(Sponsoring information)
\section{Abstract}

The principal objective of the study is to investigate the impact of intrinsic and extrinsic rewards on teachers' creativity. Teachers' creativity is used as dependent variable while intrinsic and extrinsic rewards are used as independent variables. The data are collected from 150 respondents through questionnaires. The principal component analysis (PCA) is applied to check the data validity. The reliability analysis is also performed to make the data reliable. Ordinary least square regression method is used to analyze the impact. The study reveals a positive impact of intrinsic rewards on teachers' creativity. The extrinsic rewards also have positive impact on teachers' creativity. It is concluded that rewards enhances creativity behavior of employees. The study recommends increasing intrinsic and extrinsic rewards to enhance teachers' creativity.
\end{abstract}

Keywords: Intrinsic Rewards, Extrinsic Rewards, Teachers Creativity

DOI: $10.7176 /$ RHSS/9-11-04

Publication date: June $30^{\text {th }} 2019$

\section{Introduction}

Creative behavior of employees is considered to be a robust driver of organizational survival, success and performance in short as well as long run situation (Hunter, Bedell and Mumford, 2007 and Anderson, Potoenik, and Zhou, 2014). This is the need of creativity which influences both academia and industry (Bodla and Naeem, 2014). In order to enhance this creativity, many organizations develop different reward systems to enhance the creative behavior of employees (Edwards, 1989). There has been an extensive debate on the factors explaining creative behavior of employees. An area of creative research attracts considerable interest of research for the impact of intrinsic and extrinsic rewards on creative behavior of employees.

The debate on the association between creativity and rewards is as old as the research on employee creativity behavior itself (Cummings, 1965 and Glucksberg, 1962). There are two important perspectives that are used to describe this association; the behavioral perspective and cognitive perspective. The behavioral perspective represents the extrinsic rewards as a positive supports which enhances creativity (Amabile, 1985 and Deci, Koestner and Ryan, 1999). The cognitive perspective represents extrinsic rewards as determinant of creative behavior and intrinsic motivation (Eisenberg, Pierce and Cameron, 1999; Friedman, 2009).

\subsection{Creativity}

Creativity is defined as the usage of original ideas or imaginations to create and innovate something; creativity is an important area of research that is neglected in the business research Guilford (1950). Up to now, the research in creativity witnesses tantamount growth in the efforts of research in order to identify the drivers of creative behavior of employees (Shalley, Zhou, and Oldham, 2004).

During the last five decades, the research on creativity has produced more than ten thousand studies; however, several issues are still there that creativity researchers are facing, these issues even include the definition of creativity and literature reviews on reward creativity relationship (Prabhu, Sutton and Saucer, 2008 and Batey and Furnham, 2006). Defining creativity is a complicated task as creativity is to be defined as a process of thoughts (like divergent thinking), in terms of behavior (like searching new ways for conducting same task) and in terms of final product (like investing in new plants). There are four different approaches through which creativity can be explained (Mooney, 1963):

i. The creativity process

ii. The creative product or creativity output 
iii. The creative personality or the person who brings creation

iv. The creative environment or the environment about which creation comes

On the basis of above approaches, there are number of creativity's definitions identified by Taylor (1988) over the five decades. One of these definitions is considered in this study; creativity is defined in many assorted ways that it has almost ceased to mean anything (Batey and Furnham, 2006). Creativity can also be defined as an outcome in the form of process, product or service which is useful as well as innovative and creative (Amabile 1996 and Amabile, 1983). This definition is frequently used by many researchers (Oldham and Cummings, 1996; Amabile, Conti, Coon, Lazenby and Herron, 1996; Fong, 2006; Gilson and Madjar, 2011 and Shalley, Gilson and Blum, 2000).

\subsection{Intrinsic and Extrinsic Rewards}

Intrinsic reward is described as the desire to accomplish an action by itself, to practice pleasure in its performance without expectation of any external reward (Sagiv, Arieli, Goldenberg, \& Goldschmidt, 2010). Intrinsic reward comes from within the worker (Amabile, Hill, Hennessey, and Tighe, 1994). For those individuals who are intrinsically motivated, a task becomes a reward for them (Lepper, Greene, and Nisbett, 1973).

Contrarily, extrinsic reward is defined as a visible and tangible thing given to an employee or individual on the basis of achievement (Deci and Ryan, 1985). Extrinsic rewards have monetary value like bonus, award, salary hike or public recognition. A relation between extrinsic reward and behavior refers to extrinsic motivation. For intrinsic motivation, there is no interaction between behavior and extrinsic rewards (Cooper and Jayatilaka, 2006).

Explaining shortly, the rewards that promote intrinsic motivation are known as intrinsic rewards, these include enjoyment, satisfaction and a sense of achievement. Alternatively, extrinsic rewards promote extrinsic motivation which includes financial and non-financial rewards like recognition and promotion.

\subsection{Objectives of the Study}

The objective of the study is:

i. To investigate the impact of intrinsic rewards on teachers' creativity.

ii. To quantify the effect of extrinsic rewards on teachers' creativity.

iii. To provide useful guidelines to the policy makers as well as to the future researchers.

The remaining paper is organized as follows: section two explains the review of previous literature and development of hypothesis, section three presents the data and research methodology, section four describes the empirical results and discussions, section five provides the conclusion and paper ends with some future direction and limitations.

\section{Literature Review}

Balkin, Roussel and Werner (2013) studied the extrinsic rewards and their implications for creativity. They gathered data from 300 respondents through structured questionnaires. They found a direct association between extrinsic rewards and creativity. A significant relationship among low pay intensity, choice over timing, generalized outcomes of pay performance contingent pay, ex-post basis of pay and creativity was also found. Bodla and Naeem (2014) analyzed the mediating impact of creativity on the relationship between rewards motivation and performance of the organizations operating in India. The data from 180 respondents were collected through questionnaires. Performance was used as dependent variable while rewards motivation was used as independent variable. Creativity was used as mediating variable. They suggested that rewards motivations increased creativity which ultimately promoted performance.

Conti, Collins and Picariello (2001) demonstrated the effect of competition on intrinsic rewards and creativity. They observed a positive relationship between competition and intrinsic reward and negative relationship between intrinsic rewards and creativity. They found less creativity in females as compare to males. Males were also found to be more motivated (extrinsic and intrinsic) in the environment of competition than females. De Jesus, Rus, Lens and Imaginario (2013) studied the relationship between creativity and intrinsic rewards motivation. They used creativity as dependent variable and intrinsic rewards as independent variables. 302 questionnaires were filled out to collect the data. They found a positive interaction between intrinsic rewards and creativity. Furthermore, they also identified research design as a moderator between intrinsic rewards and creativity.

Deci, Koestner and Ryan (2001) identified the impact of extrinsic and intrinsic rewards in education sector of United States. The required data were gathered through structured interviews from 508 respondents. They found a negative relationship between monetary rewards and intrinsic motivation and a positive relationship between extrinsic rewards and motivation. They further said that all types of extrinsic rewards declined the intrinsic motivation. Eisenberger and Aselage (2009) investigated the impact of rewards on performance 
pressure, intrinsic interest and creativity. The structured interviews were conducted from 609 respondents of USA residents. They said that expected reward paid for high performance motivated the worker for higher performance which ultimately increased creativity and interest. Eisenberg and Thompson (2011) observed the association between creative performance, stress, motivation rewards and competition. They found that competition increased motivation, motivation enhanced rewards, rewards increased creativity and creativity enhanced stress.

Friedman (2009) analyzed the impact of rewards on creativity. The data from United States' respondents were gathered through well-structured questionnaires. Creativity was used as dependent variable while extrinsic and intrinsic rewards were used as independent variables. A positive relationship between rewards and creativity was found. It was concluded that extrinsic and intrinsic rewards enhanced creativity with the condition that the rewards were to be paid upon creative performance. Grant and Berry (2011) studied the association among perspective talking, pro-social and intrinsic motivations and creativity. The data were gathered from the Indian respondents through interviews. A positive relationship between intrinsic motivation and creativity was found. Furthermore, it was also found that creativity strengthen the pro-social motivation and enhanced performance. Malik, Butt and Choi (2015) analyzed the relation between creative performance of employees and rewards with the moderating impact of locus of control, importance of rewards and creative self-efficacy. They observed a positive influence of extrinsic rewards on creativity. The relation between extrinsic rewards and creativity was moderated by personal disposition, values and locus of control. Navaresse Yauch Goff and Fonseca (2014) explained the impact of rewards, creativity, and organizational culture on workgroup performance of workers working in United States' organizations. A significant relationship between creative performance and individual creativity was found. They did not find any relationship between rewards and creative behavior of individuals. Wiltermuth and Gino (2013) analyzed whether intrinsic and extrinsic rewards increase motivation. They used rewards as independent variable and motivation and creativity as dependent variables. The study was conducted in the organizations working in India. They concluded that rewards significantly increased motivation and motivation, in turn, enhanced creativity.

Roskes, Dreu and Nijstad (2012) analyzed the impact of rewards and motivations on creativity and performance. They collected data from 302 respondents of United States. They found that there was a positive relation between rewards and creativity and rewards and performance. The individuals who avoided motivation were found less motivated than the individual who were highly motivated. Yoon, Sung and Choi (2015) studied the perceptions of employees towards extrinsic and intrinsic rewards for creativity. The survey was conducted on more than seven hundred employees. A significant interaction was found between extrinsic and intrinsic rewards and creativity. They concluded that relationship between rewards and creativity was moderated through importance of rewards. Zhang, Long, Wu and Huang (2015) investigated the creativity of employees related to pay for performance in Chinese context. The data of 107 Chinese respondents were collected through structured questionnaires. They found a positive effect of performance based pay on creativity. It was observed that human resource practices weakened the positive association between performance based pay and creativity.

\subsection{Development of Hypotheses}

On the basis of above literature, the following hypotheses are constructed:

$\mathrm{H}_{1}$ : There is a positive impact of intrinsic rewards on teachers' creativity.

$\mathrm{H}_{2}$ : There is a positive impact of extrinsic rewards on teachers' creativity.

\section{Data and Methodology}

The study investigates the impact of extrinsic and intrinsic rewards on teachers' creativity. The data are collected from 150 respondents through well-designed questionnaires. The closed-ended questions are used in the questionnaire. All the items used in the questionnaires are adopted from previous researches. The principal component analysis (PCA) is applied to check the data validity. The reliability analysis is performed to make the data reliable. Finally, the ordinary least square method is used to analyze the impact of intrinsic and extrinsic rewards on teachers' creativity.

\subsection{Variables Description}

Two types of variables are used in the study; dependent and independent variables. The description of variables is given below:

\subsubsection{Dependent Variable - Teachers Creativity}

During the last five decades, the research on creativity has produced more than ten thousand studies; however, several issues are still there that creativity researchers are facing, these issues even include the definition of creativity (Prabhu, Sutton and Saucer, 2008 and Batey and Furnham, 2006). Defining creativity is a complicated task as creativity is to be defined as a process of thoughts (like divergent thinking), in terms of behavior (like searching new ways for conducting same task) and in terms of final product (like investing in new plants). 
Creativity is defined as the usage of original ideas or imaginations to create and innovate something (Guilford, 1950). Creativity is also defined as an outcome in the form of process, product or service which is useful as well as innovative and creative (Amabile 1996 and Amabile, 1983). This definition is frequently used by many researchers (Oldham and Cummings, 1996; Amabile, Conti, Coon, Lazenby and Herron, 1996; Fong, 2006; Gilson and Madjar, 2011 and Shalley, Gilson and Blum, 2000).

3.1.2 Independent Variables - Intrinsic and Extrinsic Rewards

Intrinsic reward is described as the desire to accomplish an action by itself, to practice pleasure in its performance without expectation of any external reward (Sagiv, Arieli, Goldenberg, \& Goldschmidt, 2010). Intrinsic reward comes from within the worker (Amabile, Hill, Hennessey, and Tighe, 1994). In contrast, extrinsic reward is defined as a visible and tangible thing given to an employee or individual on the basis of achievement (Deci and Ryan, 1985). Extrinsic rewards have monetary value like bonus, award, salary hike or public recognition. A relation between extrinsic reward and behavior refers to extrinsic motivation (Cooper and Jayatilaka, 2006).

\subsection{Econometric Model}

The following econometric model is used to analyze the impact of intrinsic and extrinsic rewards on teachers' creativity:

Teachers Creativity $=\beta 0+\beta 1$ (Intrinsic Rewards $)+\beta 2($ Extrinsic Rewards $)+e$

\section{Results and Discussions}

This section presents the results of PCA, descriptive statistics, reliability test, correlation analysis and regression analysis. Table 1 shows the demographic information of respondents. A total of 166 questionnaires are distributed to the teachers of both public and private colleges of city Lahore, Pakistan. Respondents return 150 questionnaires with a high response rate of $90 \%$. The demographic information of respondents is presented in Table 1. 65.33\% respondents are males while $34.67 \%$ are females. Out of total 150 respondents, $41.33 \%$ are within the age of 20-24 years while $21.34 \%$ are within the age of 35-44 years; the rest 37.33 respondents have the age of 25-34 years. 47.86\% respondents have higher qualification of Masters of Philosophy. 12.67\% (39.47\%) respondents posit bachelors (masters) qualifications. The preferred language of 54\% (46\%) respondents is English (Urdu). 54.67\% respondents belong to public institutes while $45.33 \%$ belong to private institutes.

Analysis on larger amount of data is very difficult to handle, the study reduces the data from large number of items to smaller number of constructs through factor analysis (principle component analysis). The principle component analysis posits that the value of KMO must exceed 0.6 and the level of significance (Bartlett test) should be less than 0.05 . Once these assumptions are fulfilled, the principle component analysis (PCA) reduces data through variance rotation method. PCA gives Eigen values and those constructs are considered principle component whose Eigen values are greater than 1. If only one Eigen value exceeds 1, it means there is only one principle component which shows that all the values are loaded into a single component and all the loading values must exceeds 0.40 ; here, the data are considered to be valid and it is known as convergent validity. Again, if more than one Eigen values exceed 1, it means that there are more than one principle components, meaning that all the values are loaded in more than one component. In this case, the data have two values; loading values and cross loading values. The larger value of all the components is considered as the loading value while the smaller value is considered as cross loading value. In this situation, loading values should exceed 0.4 and cross loading values should be less than 0.4 ; here, the data are considered to be valid and is known as discriminate validity. Shortly, when only 1 Eigen value exceeds 1, this is convergent validity and when more than one Eigen values exceeds 1 , this is discriminate validity.

Table 2 shows the presumptions of PCA, the value of KMO for all components exceeds 0.60 and the significance level of Bartlett's Test of Sphericity is less than 0.05, so the study can go for further analysis. Those components of a construct considered to be a principle component that has an Eigen value greater than 1. Table 3 shows the Eigen value (as well as total variance explained by each Eigen value) of each component. Two components are extracted from the five constructs (salary, performance bonus, career development, development opportunities, employee satisfaction and job performance) of rewards and teacher creativity. Whereas, only one component is extracted from the two constructs (promotion and working conditions). So, discriminate validity is analyzed from those constructs having two components and convergent validity is analyzed from those having one component.

Table 4 provides the validities of all the measures used in the instrument. Two constructs of promotion and working conditions have only one Eigen value which is greater than 1. The related items of these two components are loaded only in one component, and all the items have values greater than 0.4 . It posits that there exists convergent validity in the data.

All the constructs' items of salary, performance bonus, career development, development opportunities, employee satisfaction, job performance are loaded in two components, all the loaded values exceed 0.4 and all 
the cross loading values are less than 0.4 . There is presence of discriminate validity in the data. The above arguments demonstrate that all the data collected through instruments are valid.

In order to determine the internal consistency (reliability) of the instrument, the reliability test is also applied. Table 5 shows that all the variables have alpha coefficient above 0.70; showing that the instrument is reliable. Salary, performance bonus, promotion, career development, development opportunities, working conditions, employee satisfaction and job performance has alpha coefficient of $0.78,0.71,0.90,0.82,0.79,0.73$, 0.70 and 0.74 respectively.

Table 6 reports the descriptive statistics outcomes of all the variables used in the study. The mean value of salary is 4.14 ranging from 2 to 4 . The average value of performance bonus, promotion, career development, development opportunities, working conditions, employee satisfaction and job performance is 4.32, 4.21, 4.17, $3.98,2.18$ and 4.97 respectively.

The correlation analysis is used to predict the nature of correlation. Table 7 presents the results of Pearson Correlation Matrix for dependent and independent variables. There is week correlation among all the variables. The highest correlation coefficient $(0.45)$ is in between teacher creativity and extrinsic rewards. It shows that multicollinearity does not affect the data.

Table 8 presents the results of regression analysis for the impact of intrinsic and extrinsic rewards on teachers' creativity. There is significant positive $(\beta=0.0632, p<0.05)$ impact of intrinsic rewards on teachers' creativity. The positive coefficient of intrinsic rewards shows that increasing $1 \%$ of rewards leads to increase teachers' creativity by $6.3 \%$. The extrinsic rewards also show significant positive $(\beta=0.0248, \mathrm{p}<0.05)$ impact on teachers' creativity. One percent increase in extrinsic rewards causes to increase teachers' creativity by $2.4 \%$. The results are consistent with previous studies. (Yoon, Sung and Choi, 2015; Zhang, Long, Wu and Huang, 2015; Malik, Butt and Choi 2015; Bodla and Naeem, 2014; Navaresse Yauch Goff and Fonseca, 2014; Wiltermuth and Gino, 2013; Balkin, Roussel and Werner, 2013; De Jesus, Rus, Lens and Imaginario, 2013; Grant and Berry, 2011; Eisenberg and Thompson, 2011; Sagiv, Arieli, Goldenberg and Goldschmidt, 2010; Eisenberger and Aselage, 2009; Friedman, 2009; Conti, Collins and Picariello, 2001; Deci, Koestner and Ryan, 2001).

Rewards motivations increase teachers' creativity which ultimately promotes performance. Expected reward against high performance motivates the worker for higher performance which ultimately increase creativity and interest (Eisenberg and Thompson, 2011). The teachers should be competent as the competition increases motivation, motivation enhances performance, performance increase rewards, and rewards increase creativity and creativity increase competition (Sagiv, Arieli, Goldenberg and Goldschmidt, 2010), and the cycle begins again from competition. Extrinsic and intrinsic rewards enhance creativity with the condition that the rewards are to be paid upon creative performance.

\section{Conclusions}

Creative behavior of employees is considered to be a robust driver of organizational survival, success and performance in short as well as long run situation (Hunter, Bedell and Mumford, 2007 and Anderson, Potoenik, and Zhou, 2014). This is the need of creativity which influences both academia and industry (Bodla and Naeem, 2014). In order to enhance this creativity, many organizations develop different reward systems to enhance the creative behavior of employees (Edwards, 1989). There has been an extensive debate on the factors explaining creative behavior of employees. An area of creative research attracts considerable interest of research for the impact of intrinsic and extrinsic rewards on creative behavior of employees.

The study, therefore, investigates the impact of extrinsic and intrinsic rewards on teachers' creativity. The data are collected from 150 respondents through well-designed questionnaires. The closed-ended questions are used in the questionnaire. The principal component analysis (PCA) is applied to check the data validity. The reliability analysis is performed to make the data reliable. Finally, the ordinary least square method is used to analyze the impact of intrinsic and extrinsic rewards on teachers' creativity.

There is significant positive impact of intrinsic rewards on teachers' creativity. The positive coefficient of intrinsic rewards shows that increasing $1 \%$ of rewards leads to increase teachers' creativity by $6.3 \%$. The extrinsic rewards also show significant positive impact on teachers' creativity. One percent increase in extrinsic rewards causes to increase teachers' creativity by $2.4 \%$. Rewards motivations increase teachers' creativity which ultimately promotes performance. Expected reward against high performance motivates the worker for higher performance which ultimately increase creativity and interest (Eisenberg and Thompson, 2011). The teachers should be competent as the competition increases motivation, motivation enhances performance, performance increase rewards, and rewards increase creativity and creativity increase competition (Sagiv, Arieli, Goldenberg and Goldschmidt, 2010), and the cycle begins again from competition. Extrinsic and intrinsic rewards enhance creativity with the condition that the rewards are to be paid upon creative performance. It is concluded that rewards enhances creativity behavior of employees. The study recommends increasing intrinsic and extrinsic rewards to enhance teachers' creativity. 


\subsection{Limitations and Directions for Future Research}

The study has some limitations and directions for future research:

i. The study only used cross-sectional design; future researchers can use longitudinal design to analyze the impact of intrinsic and extrinsic rewards on creativity.

ii. The study only focused on quantitative data through questionnaires, future study may be conducted through qualitative data using interviews technique.

iii. Due to limited time, the study only focused on a specific area of city Lahore, Pakistan, future research could be undertaken in the other areas of Pakistan.

\section{References}

Amabile, T. M. (1983). The social psychology of creativity. New York: Springer - Verlag.

Amabile, T. M. (1985). Motivation and creativity: Effects of motivational orientation on creative writers. Journal of personality and social psychology, 48(2), 393.

Amabile, T. M., Conti, R., Coon, H., Lazenby, J., and Herron, M. (1996). Assessing The Work Environment For Creativity. Academy of Management Journal, 39(5), 1154-1184.

Amabile, T. M., Hill, K. G., Hennessey, B. A., and Tighe, E. M. (1994). The Work Preference Inventory: Assessing Intrinsic and Extrinsic Motivational Orientations. Journal of personality and social psychology, 66(5), 950-967.

Anderson, N., Potočnik, K., and Zhou, J. (2014). Innovation and Creativity in Organizations A State-of-the Science Review, Prospective Commentary, and Guiding Framework. Journal of Management, 40(5), 1297 1333.

Balkin, D. B., Roussel, P., and Werner, S. (2013). Extrinsic Rewards and Autonomy: Implications for Rewarding Creativity. Paper presented at the Academy of Management Proceedings.

Batey, M., and Furnham, A. (2006). Creativity, Intelligence, and Personality: A Critical Review of the Scattered Literature. Genetic, Social and General Psychology Monographs, 132(4), 355-429.

Bodla, M. A., and Naeem, B. (2014). Creativity as Mediator for Intrinsic Motivation and Sales Performance. Creativity Research Journal, 26(4), 468-473.

Bodla, M. A., and Naeem, B. (2014). Creativity as Mediator for Intrinsic Motivation and Sales Performance. Creativity Research Journal, 26(4), 468-473.

Conti, R., Collins, M. A., and Picariello, M. L. (2001). The impact of competition on intrinsic motivation and creativity Personality and individual Differences, 30, 1273-1289

Cooper, R. B., and Jayatilaka, B. (2006). Group Creativity: The Effects of Extrinsic, Intrinsic, and Obligation Motivations. Creativity Research Journal, 18(2), 153-172.

Cummings, L. (1965). Organizational climates for creativity. The Academy of Management Journal, 8(3), 220227.

De Jesus, S. N., Rus, C. L., Lens, W., and Imaginario, S. (2013). Intrinsic Motivation and Creativity Related to Product: A Meta-analysis of the Studies Published Between 1990-2010. Creativity Research Journal, 25(1), 80-84.

Deci, E. L., and Ryan, R. M. (1985). Intrinsic motivation and self-determination in human behavior. New York: Plenum.

Deci, E. L., Koestner, R., and Ryan, R. (1999). A meta-analytic review of experiments examining the role of extrinsic rewards on intrinsic motivation. Journal of Applied Psychology.

Deci, E. L., Koestner, R., and Ryan, R. M. (2001). Extrinsic Rewards and Intrinsic Motivation in Education: Reconsidered Once Again. Review of Educational Research, 71(1), 1-27.

Edwards, M. R. (1989). Measuring. Creativity at Work: Developing a Reward-For-Creativity Policy. The Journal of Creative Behavior, 23(1), 26-37.

Eisenberg, J., and Thompson, W. F. (2011). The effects of competition on improvisers' motivation, stress, and creative performance. Creativity Research Journal, 23(2), 129-136.

Eisenberger, R., and Aselage, J. (2009). Incremental effects of reward on experienced performance pressure: positive outcomes for intrinsic interest and creativity. Journal of Organizational Behavior, 30(1), 95-117.

Eisenberger, R., Pierce, W. D., and Cameron, J. (1999). Effects of Reward on Intrinsic Motivation - Negative, Neutral and Positive. Psychological Bulletin, 125(6), 677-691.

Fong, C. T. (2006). The Effects of Emotional Ambivalence on Creativity. Academy of Management Journal, 49(5), 1016-1030.

Friedman, R. S. (2009). Reinvestigating the effects of promised reward on creativity. Creativity Research Journal, 21(2-3), 258-264.

Friedman, R. S. (2009). Reinvestigating the effects of promised reward on creativity. Creativity Research Journal, 21(2-3), 258-264.

Gilson, L. L., and Madjar, N. (2011). Radical and incremental creativity: Antecedents and processes. Psychology 
of Aesthetics, Creativity, and the Arts, 5(1), 21-28.

Glucksberg, S. (1962). The influence of strength of drive on functional fixedness and perceptual recognition. Journal of Experimental Psychology, 63(1), 36.

Grant, A. M., and Berry, J. W. (2011). The Necessity of Others is the Mother of Invention: Intrinsic and Prosocial Motivations, Perspective Taking, and Creativity. Academy of Management Journal, 54(1), 73-96.

Guilford, J. P. (1950). Creativity. American Psychologist, 5, 444 - 454.

Hunter, S. T., Bedell, K. E., and Mumford, M. D. (2007). Climate for Creativity: A Quantitative Review. Creativity Research Journal, 19(1), 69-90.

Lepper, M. R., Greene, D., and Nisbett, R. E. (1973). Undermining children's intrinsic interest with extrinsic reward: A test of the overjustification hypothesis. Journal of personality and social psychology, 28, 129-137.

Malik, M. A. R., Butt, A. N., and Choi, J. N. (2015). Rewards and employee creative performance: Moderating effects of creative self-efficacy, reward importance, and locus of control. Journal of Organizational Behavior, 36(1), 59-74.

Mooney, R. L. (1963). A conceptual model for integrating four approaches to the identification of creative talent in Scientific Creativity: Its Recognition and Development, ed. CW Taylor and F. Barron. In C. W. Taylor and F. Barrons (Eds.), Scientific Creativity: its recognition and development (pp. 331- 340).

Navaresse, D. O., Yauch, C. A., Goff, K., and Fonseca, D. J. (2014). Assessing the Effects of Organizational Culture, Rewards, and Individual Creativity on Technical Workgroup Performance. Creativity Research Journal, 26(4), 439-455.

Prabhu, V., Sutton, C., and Sauser, W. (2008). Creativity and certain personality traits: Understanding the mediating effect of intrinsic motivation. Creativity Research Journal, 20(1), 53-66.

Roskes, M., De Dreu, C. K., and Nijstad, B. A. (2012). Necessity is the mother of invention: avoidance motivation stimulates creativity through cognitive effort. Journal of personality and social psychology, 103(2), 242

Sagiv, L., Arieli, S., Goldenberg, J., and Goldschmidt, A. (2010). Structure and freedom in creativity: The interplay between externally imposed structure and personal cognitive style. Journal of Organizational Behavior, 31(8).

Sagiv, L., Arieli, S., Goldenberg, J., and Goldschmidt, A. (2010). Structure and freedom in creativity: The interplay between externally imposed structure and personal cognitive style. Journal of Organizational Behavior, 31(8).

Selart, M., Nordström, T., Kuvaas, B., and Takemura, K. (2008). Effects of reward on self-regulation, intrinsic motivation and creativity. Scandinavian Journal of Educational Research, 52(5), 439-458.

Shalley, C. E., Gilson, L. L., and Blum, T. C. (2000). Matching Creativity Requirements and the Work Environment: Effects on Satisfaction and Intentions to Leave. Academy of Management Journal, 43(2), 215-223.

Shalley, C. E., Zhou, J., and Oldham, G. R. (2004). The effects of personal and contextual characteristics on creativity: Where should we go from here? Journal of Management, 30(6), 933-958.

Taylor, C. W. (1988). Various approaches to and definitions of creativity. In R. J. Sternberg (Ed.), The concept of creativity: Contemporary Psychological Perspectives (pp. 99-121). Cambridge, England: Cambridge University Press.

Wiltermuth, S. S., and Gino, F. (2013). "I'll have one of each": How separating rewards into (meaningless) categories increases motivation. Journal of personality and social psychology, 104(1), 1-13.

Yoon, H. J., Sung, S. Y., \& Choi, J. N. (2015). Mechanisms underlying creative performance: employee perceptions of intrinsic and extrinsic rewards for creativity. Social Behavior and Personality: An international journal, 43(7), 1161-1179.

Zhang, Y., Long, L., Wu, T. y., and Huang, X. (2015). When is pay for performance related to employee creativity in the Chinese context? The role of guanxi HRM practice, trust in management, and intrinsic motivation. Journal of Organizational Behavior. 


\section{APPENDIX}

Table 1: Demographic Information of Respondents

\begin{tabular}{|l|c|c|c|}
\hline Demographics & Particulars & Frequency & Percentage \\
\hline \multirow{3}{*}{ Gender } & Male & 98 & 65.33 \\
\cline { 2 - 4 } & Female & 52 & 34.67 \\
\cline { 2 - 4 } & $20-24$ & 62 & 41.33 \\
\cline { 2 - 4 } & $25-34$ & 56 & 37.33 \\
\hline \multirow{3}{*}{ Qualification } & $35-44$ & 32 & 21.34 \\
\cline { 2 - 4 } & Bachelors & 19 & 12.67 \\
\cline { 2 - 4 } & Masters & 60 & 39.47 \\
\hline Language & M.Phil. & 71 & 47.86 \\
\cline { 2 - 4 } & English & 81 & 54.00 \\
\hline Institute & Urdu & 69 & 46.00 \\
\cline { 2 - 4 } & Public & 68 & 55.33 \\
\cline { 2 - 4 } & Private & 82 & 54.67 \\
\hline
\end{tabular}

Table 2: KMO and Bartlett Test Significance

\begin{tabular}{|l|c|c|c|}
\hline Constructs & No. of items & KMO & $\begin{array}{c}\text { Bartlett't test of Sphericity } \\
\text { Significance }\end{array}$ \\
\hline Salary & 4 & 0.8216 & 0.000 \\
\hline Performance Bonus & 4 & 0.7328 & 0.000 \\
\hline Promotion & 3 & 0.9318 & 0.000 \\
\hline Career Development & 4 & 0.9821 & 0.000 \\
\hline Development Opportunities & 4 & 0.9120 & 0.000 \\
\hline Working Conditions & 3 & 0.7000 & 0.000 \\
\hline Employee Satisfaction & 6 & 0.8271 & 0.000 \\
\hline Job Performance & 6 & 0.8216 & 0.000 \\
\hline
\end{tabular}

Note: The value of KMO shows "in the 0.90s: Marvelous, in the 0.80s: Meritorious, in the 0. 70s: Middling, in the 0.60s: Mediocre, in the 0.50s: Miserable, Below 0.50: Unacceptable".

Table 3: Eigen Values and Total Variance Explained

\begin{tabular}{|l|c|c|c|}
\hline Constructs & Components & Eigen Values & Total Variance Explained \\
\hline Salary & Comp 1 & 1.689 & 42.223 \\
& Comp 2 & 1.254 & 31.342 \\
\hline Performance Bonus & Comp 1 & 1.266 & 31.656 \\
& Comp 2 & 1.156 & 28.898 \\
\hline Promotion & Comp 1 & 1.187 & 35.156 \\
\hline Career Development & Comp 1 & 1.307 & 32.683 \\
& Comp 2 & 1.091 & 27.285 \\
\hline Development Opportunities & Comp 1 & 1.652 & 41.299 \\
& Comp 2 & 1.175 & 29.376 \\
\hline Working Conditions & Comp 1 & 1.275 & 42.492 \\
\hline Employee Satisfaction & Comp 1 & 1.795 & 29.915 \\
& Comp 2 & 1.382 & 23.028 \\
\hline Job Performance & Comp 1 & 1.864 & 47.726 \\
& Comp 2 & 1.409 & 23.475 \\
\hline
\end{tabular}


Table 4: Validities of Measurements

\begin{tabular}{|l|c|c|l|l|c|}
\hline Items & \multicolumn{2}{|c|}{ Components } & Items & \multicolumn{2}{c|}{ Components } \\
\hline Salary & Comp 1 & Comp 2 & Working Conditions & \multicolumn{2}{c|}{ Comp 1 } \\
\hline S1 & $\mathbf{0 . 4 5 6}$ & 0.244 & W1 & 0.987 & 0.876 \\
\hline S2 & $\mathbf{0 . 6 7 8}$ & 0.378 & W2 & 0.782 & \\
\hline S3 & 0.239 & $\mathbf{0 . 6 7 9}$ & W3 & Comp 1 & Comp 2 \\
\hline S4 & 0.345 & $\mathbf{0 . 7 8 8}$ & Employee Satisfaction & -0.580 & $\mathbf{0 . 5 9 8}$ \\
\hline Performance Bonus & Comp 1 & Comp 2 & E1 & -0.020 & $\mathbf{0 . 8 6 5}$ \\
\hline B1 & $\mathbf{0 . 7 6 4}$ & -0.137 & E2 & 0.383 & $\mathbf{0 . 7 1 3}$ \\
\hline B2 & $\mathbf{0 . 7 7 4}$ & 0.169 & E3 & $\mathbf{0 . 7 6 9}$ & 0.113 \\
\hline B3 & 0.163 & $\mathbf{0 . 7 6 5}$ & E3 & $\mathbf{0 . 7 4 9}$ & 0.135 \\
\hline B4 & -0.131 & $\mathbf{0 . 7 5 0}$ & E4 & 0.015 & $\mathbf{0 . 6 3 5}$ \\
\hline Promotion & Comp 1 & & E5 & 0.345 & 0.786 \\
\hline P1 & 0.897 & & E6 & Comp 1 & Comp 2 \\
\hline P2 & 0.876 & & Job Performance & 0.634 & -0.407 \\
\hline P3 & 0.765 & & J1 & -0.871 & $\mathbf{0 . 7 9 3}$ \\
\hline Career Development & Comp 1 & Comp 2 & J2 & -0.183 & $\mathbf{0 . 8 9 1}$ \\
\hline C1 & $\mathbf{0 . 8 5 4}$ & -0.059 & J3 & -0.246 & $\mathbf{0 . 8 4 5}$ \\
\hline C2 & $\mathbf{0 . 8 8 7}$ & 0.051 & J4 & $\mathbf{0 . 9 0 3}$ & -0.003 \\
\hline C3 & 0.280 & $\mathbf{0 . 8 0 4}$ & J5 & $\mathbf{0 . 9 2 0}$ & -0.031 \\
\hline C4 & -0.305 & $\mathbf{0 . 7 7 5}$ & J6 & & \\
\hline Development Opportunities & Comp 1 & Comp 2 & & & \\
\hline D1 & -0.208 & $\mathbf{0 . 8 2 3}$ & & & \\
\hline D2 & 0.345 & $\mathbf{0 . 7 7 9}$ & & & \\
\hline D3 & $\mathbf{0 . 8 3 3}$ & 0.252 & & & \\
\hline D4 & $\mathbf{0 . 7 4 3}$ & -0.159 & & & \\
\hline
\end{tabular}

Table 5: Reliability Test

\begin{tabular}{|l|c|c|}
\hline Construct & Number of Items & Cronbach's Alpha (a) \\
\hline Salary & 4 & 0.7824 \\
\hline Performance Bonus & 4 & 0.7158 \\
\hline Promotion & 3 & 0.9010 \\
\hline Career Development & 4 & 0.8214 \\
\hline Development Opportunities & 4 & 0.7924 \\
\hline Working Conditions & 3 & 0.7328 \\
\hline Employee Satisfaction & 6 & 0.7012 \\
\hline Job Performance & 6 & 0.7421 \\
\hline
\end{tabular}

Note: Acceptable if $a>0.70$.

Table 6: Descriptive Statistics

\begin{tabular}{|l|c|c|c|c|c|}
\hline Particulars & $\mathbf{N}$ & Minimum & Maximum & Mean & S.D \\
\hline Salary & 150 & 2.00 & 4.00 & 4.1478 & 0.8521 \\
\hline Performance Bonus & 150 & 2.00 & 3.00 & 4.3214 & 0.3627 \\
\hline Promotion & 150 & 2.00 & 5.00 & 4.2147 & 0.2587 \\
\hline Career Development & 150 & 2.00 & 4.00 & 4.1789 & 0.3258 \\
\hline Development Opportunities & 150 & 2.00 & 4.00 & 3.9831 & 0.9632 \\
\hline Working Conditions & 150 & 2.00 & 4.00 & 3.8214 & 0.3147 \\
\hline Employee Satisfaction & 150 & 1.00 & 4.00 & 2.1874 & 0.8147 \\
\hline Job Performance & 150 & 2.00 & 5.00 & 4.9712 & 0.2871 \\
\hline
\end{tabular}

Table 7: Pearson Correlation Matrix

\begin{tabular}{|l|c|c|c|}
\hline Variables & Teachers Creativity & Extrinsic Rewards & Intrinsic Rewards \\
\hline Teachers Creativity & 1 & & \\
\hline Extrinsic Rewards & 0.4587 & 1 & \\
\hline Intrinsic Rewards & 0.3652 & 0.4215 & 1 \\
\hline
\end{tabular}


Table 8: Regression Analysis [Dependent Variables: Teachers Creativity]

\begin{tabular}{|l|c|c|c|}
\hline Variables & Coefficient & t-statistics & p-value \\
\hline Constant & 0.0258 & 2.0145 & $0.0256^{*}$ \\
\hline Intrinsic Rewards & 0.0632 & 3.0258 & $0.0148^{*}$ \\
\hline Extrinsic Rewards & 0.0248 & 4.3684 & $0.0000^{*}$ \\
\hline $\mathbf{R}^{\mathbf{2}}$ & & 0.6258 & \\
\hline Adjusted $\mathbf{R}^{\mathbf{2}}$ & & 0.5935 & \\
\hline
\end{tabular}

Note: $\left.{ }^{*}\right)$ shows level of significance at $5 \%$.

\section{IMPACT OF REWARD ON TEACHERS CREATIVITY}

\section{Dear Respondent,}

I am evaluating the impact of reward on teacher's creativity. The information provided by you will assist me in shaping my research. Please take a moment to complete this survey for the current one-way trip that you are making. "Thank you".

\section{SECTION 1: DEMOGRAPHIC INFORMATION}

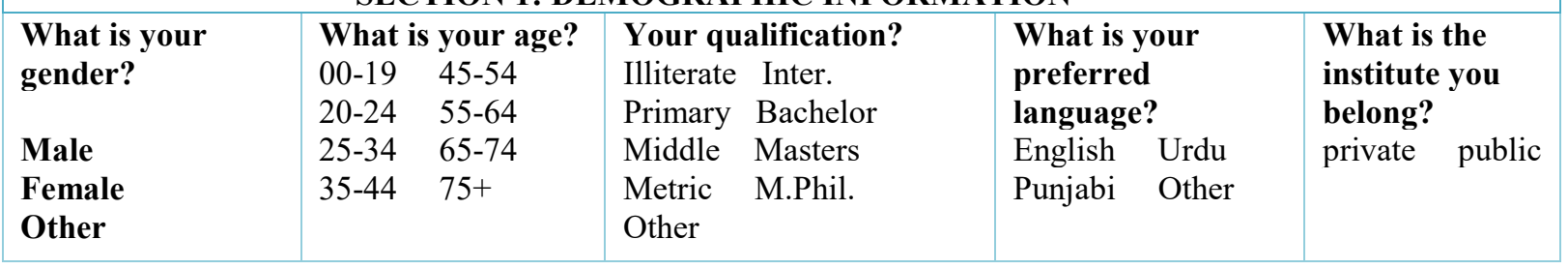


SECTION 2: EXTRINSIC REWARD

Sr. 1: strongly disagree, 2: disagree, 3: neutral, 4: Agree, 5: strongly agree Particulars

SALARY

S1 $\quad$ Your organization access your chances of salary improvement periodically

S2 $\quad$ Your organization gives you salary equivalent to your job task

S3 Your organization gives you salary on time which motivates you to perform better

S4 Your organization increases the salary of its employees based on their performance

\section{PERFORMANCE BONOUS}

B1 $\quad$ Your organization provides organization bonus to boost your motivation

B2 $\quad$ Your organization recognized your extra effort with bonus

B3 Your organization gives bonus on individual performance

B4 If you work harder your organization gives more bonus

\section{PROMOTION}

\section{P1 $\quad$ Your organization gives promotion on individual performance \\ P2 $\quad$ You organization gives promotion on experience basis \\ P3 $\quad$ Organization gives promotions only its old employees}

\section{SECTION 2: INTRINSIC REWARD}

1: strongly disagree, 2: disagree, 3: neutral, 4: Agree, 5: strongly agree

\begin{tabular}{|c|c|c|c|c|c|c|}
\hline Sr. & Particulars & 1 & 2 & \begin{tabular}{l|l}
3 & 2 \\
2
\end{tabular} & & \\
\hline \multicolumn{7}{|c|}{ Career development } \\
\hline $\mathrm{C} 1$ & Employee receive regular development through workshops & & & & & \\
\hline $\mathrm{C} 2$ & Your organization will pay for your training & & & & & \\
\hline $\mathrm{C} 3$ & Your organization emphasize its employees to seek assistance from professionals & & & & & \\
\hline $\mathrm{C} 4$ & The manager supports career development plans & & & & & \\
\hline \multicolumn{7}{|c|}{ Development opportunities } \\
\hline D1 & Your organization invest in training of employees & & & & & \\
\hline $\mathrm{D} 2$ & Your organization dictates strongly on career development & & & & & \\
\hline D3 & Your organization offer you career advancement options & & & & & \\
\hline D4 & If you work harder your organization gives more bonus & & & & & \\
\hline \multicolumn{7}{|c|}{ Working conditions } \\
\hline W1 & Organization provide better working condition to enhances your performance & & & & & \\
\hline $\mathrm{W} 2$ & Organization provides freedom of opinion in decision making & & & & & \\
\hline W3 & Organization working environment is supportive & & & & & \\
\hline
\end{tabular}

\begin{tabular}{|c|c|c|c|c|c|}
\hline \multicolumn{6}{|c|}{ SECTION 4: EMPLOYEE CREATIVITY } \\
\hline Sr. & Particulars & $\mathbf{1}$ & 2 & 3 & 4 \\
\hline \multicolumn{6}{|c|}{ EMPLOYEE SATISFACTION } \\
\hline E1 & $\begin{array}{l}\text { Present pay doesn't give any significant improvement in your } \\
\text { living conditions }\end{array}$ & & & & \\
\hline E2 & $\begin{array}{l}\text { If another job will offer you more salary then you'll left this } \\
\text { organization }\end{array}$ & & & & \\
\hline E3 & Would you recommend your friend to join this organization & & & & \\
\hline E4 & Dou you feel your job is secure & & & & \\
\hline E5 & Salary is a satisfactory in relation to what you do & & & & \\
\hline E6 & Salary increment is decided on a fair manner & & & & \\
\hline \multicolumn{6}{|c|}{ JOB PERFORMANCE } \\
\hline $\mathrm{J} 1$ & You are doing only what others wanted you to do & & & & \\
\hline $\mathrm{J} 2$ & You feel pressurized to do the task well & & & & \\
\hline $\mathrm{J} 3$ & You are able to complete the objectives of organizations & & & & \\
\hline $\mathrm{J} 4$ & $\begin{array}{l}\text { After performing any task, you felt that you had perform it } \\
\text { well }\end{array}$ & & & & \\
\hline J5 & $\begin{array}{l}\text { Are you willing to Increase work Efforts in Order to Gain } \\
\text { Reward }\end{array}$ & & & & \\
\hline J6 & Incentives has a positive effect on your job performance & & & & \\
\hline
\end{tabular}

